\title{
"Utopias" institucionais antidiscriminação. As ambiguidades do direito e da política no debate feminista brasileiro*
}

\author{
José Rodrigo Rodriguez**
}

\section{Resumo}

A literatura feminista brasileira tem debatido uma série de problemas relacionados ao direito, em especial, o sentido e os limites do direito penal. O objetivo deste texto é reconstruir tais debates a partir de alguns textos-chave com o objetivo de identificar os principais problemas enfrentados por eles $e$ abrir novas perspectivas para a análise teórica e para a prática política.

Palavras-chave: Feminismo, Direito, Penal, Política, Utopia.

* Recebido para publicação em 05 de setembro de 2013, aceito em 01 de fevereiro de 2015.

** Professor de Mestrado e Doutorado em Direito da UNISINOS e Pesquisador Permanente do CEBRAP, São Leopoldo, RS, Brasil. jrodrigorodriguez@gmail.com 
298 "Utopias" institucionais antidiscriminação

Institutional Anti-Discrimination "Utopias". The Ambiguities of Law and Politics in Brazilian Feminist Debate

\begin{abstract}
The Brazilian feminist literature has been discussing a number of issues related to law, in particular the meaning and limits of criminal law. This paper aims to reconstruct such debates starting from some key texts in order both, to identify the main problems faced by them and to open new perspectives for the theoretical analysis and to the political practice.
\end{abstract}

Key Words: Feminisn, Law, Criminal, Politics, Utopia. 


\section{Introdução}

A literatura feminista brasileira tem discutido com frequência uma série de problemas jurídicos relacionados ao direito, em especial no que diz respeito à Lei Maria da Penha, diploma normativo que prevê diversos instrumentos para combater a violência contra a mulher. No entanto, ainda não é possível encontrar na bibliografia textos que organizem tais problemas $e$ discutam criticamente as alternativas institucionais em jogo.

O objetivo deste texto é suprir essa lacuna. A partir dos escritos mais importantes sobre a Lei Maria da Penha, as principais alternativas institucionais em pauta e seus dilemas serão avaliados. Sua primeira parte identifica dois grupos de questões pertinentes às características e limites do direito penal, de um lado, $e$ à criação de alternativas não penais no combate à violência, de outro. Ainda nesta parte, são discutidos os dilemas do que chamamos de pensamento utópico sobre as instituições.

A seguir, o texto mostra como a literatura feminista tem evitado o equívoco de criticar o direito a partir de formas não institucionalizadas de regulação. $O$ debate nesse campo tem girado em torno de alternativas institucionais que constroem de forma diferente a relação entre sociedade e Estado e a maneira de lidar com a violência contra a mulher. O texto mostra, ainda, como a literatura avalia o papel do direito penal e os seus limites, discute alternativas não penais para combater a violência $e$ tematiza o papel dos agentes estatais na administração da justiça $e$ na interpretação das normas.

Em sua terceira parte, o trabalho examina em detalhe as críticas feitas ao direito penal e discute a relação entre o combate à violência contra a mulher e a proteção à família, consagrada pela Lei. Em seguida, são examinadas as alternativas não penais para o combate à violência, em especial no que diz respeito à vagueza que caracteriza a regulação e o discurso dos agentes sociais sobre o assunto.

O texto levanta a hipótese de que essa vagueza possa ser explicada pela falta de mobilização social em torno de tais 
alternativas. Afinal, o movimento feminista tem concentrado suas forças na luta pela efetivação da alternativa penal. Finalmente, o artigo mostra a afinidade eletiva entre o discurso vitimizador e o modelo de juridificação característico do direito penal e sugere que essa afinidade é um obstáculo importante para se pensar alternativas jurídicas ao direito penal.

\section{Os perigos da utopia}

Em entrevista concedida a mim e a Gabriela Justino em 11 de setembro de 2012, Amelinha da Silva Telles, fundadora da União de Mulheres ${ }^{1}$, tocou em um ponto fundamental para a reflexão sobre as instituições do Estado de direito e o combate à discriminação de gênero e contra as mulheres. Ao nos relatar os fatos que marcaram o processo de elaboração e aprovação da Lei Maria da Penha e avaliar seu impacto sobre a vida das mulheres, Amelinha fez considerações importantes sobre a maneira pela qual os conflitos são acolhidos pelas delegacias de polícia em comparação, por assim dizer, com as utopias institucionais imaginadas pelo movimento feminista.

Amelinha: A própria Delegacia já perdeu muito de seu
vigor dos anos 80 , época em que ela foi criada, em 85 . Hoje
tem um homem atendendo na delegacia, um homem
atende as mulheres ali na frente no balcão. E quem fez
aquele balcão ali na frente? A delegacia tem um formato
totalmente antiacolhedor, não é? Porque é assim, você

1 Organização não governamental feminista criada em 1981, cujos objetivos são: a) Promover a participação das mulheres em defesa de seus direitos, buscando justiça e igualdade social e a consolidação da democracia; b) Capacitar profissionais para promover $\mathrm{o}$ acesso das mulheres à justiça $e$ aos direitos humanos; c) Oferecer orientação às mulheres em situação de violência e criar condições para que elas possam orientar outras mulheres sob uma perspectiva de gênero, raça, etnia, orientação sexual e relações entre gerações; d) Oferecer oficinas e grupos de vivência; e) Promover ações em parceria com ONGS e órgãos governamentais para garantir apoio e ampliação dos serviços e realização de ações conjuntas, formação de redes e formulação de políticas públicas de combate à violência; f) Realizar o projeto das Promotoras Legais Populares. 
senta e quando você é chamada "Qual que é a próxima?", e você vai lá no balcão, chegou lá no balcão, você tem que falar seu problema na frente de todo mundo e, na frente daquele funcionário que pode ser o faxineiro do prédio, pode ser quem for porque principalmente quem vai na hora do almoço, porque na hora do almoço todos da delegacia vão almoçar. (...) Aí ela tem que falar alto porque se você fala muito baixo eles falam que não estão entendendo o que ela está falando e aí ela fala, fica com vergonha porque outras pessoas estão ouvindo... (...)

Amelinha: Eu tinha um sonho de ter um lugar assim, sabe? Foi um sonho que nós tivemos, nós feministas, de ter um lugar assim, muito lindo, que a gente vê um filme, um filme americano...

E: Que filme?

Amelinha: Ah, eu não sei qual, eu sei que a gente viu um lugar assim que era uma casa cheia de jardim assim, a mulher entrava lá, era recebida, sabe? Com massagem, nossa, era uma coisa tão legal, "Ah, você continua com dor? Vamos ver, você vai passar na médica agora, vamos ver a médica", e primeiro elas passavam pelas mulheres $e$ aí depois conversavam com a assistente social para ver o problema de como vai ser o aluguel, não sei mais o que, um atendimento integral. E foi nesse sonho que nasceu a primeira Casa, essa casa nasceu desse sonho.

E.: O que é? Eu não sei o que é a Casa...

Amelinha: É uma Casa Eliane de Grammont da prefeitura para atender as mulheres em situação de violência e a ideia era que tivesse tudo na casa $e$, se você for na Vila Clementino, na Rua Doutor Bacelar, n. 20, você ainda vai ficar e falar "Nossa, o sonho mixou mesmo, acabou, o sonho acabou", porque a casinha é pequeninha, cheia de goteira, cheia de infiltração, entendeu? As técnicas, porque lá só tinham mulheres, foram se aposentando porque isso foi criado na época da Luiza Erundina, e não são substituídas e então não tem, está reduzindo o número de profissionais, o número de atendimento, mas ela nasceu dessa ideia. 
302 "Utopias" institucionais antidiscriminação

É o primeiro Centro de Referência da Mulher, tanto é que quando a gente escreve na lei "Centro de Referência da Mulher" é porque a gente tinha experiência da casa, entendeu? Quando a gente escrever "Casa Abrigo", a gente tinha experiência e lá em Porto Alegre as mulheres fizeram a Casa Abrigo que é "Viva Maria, viva", não sei, um negócio assim, um negócio lindo que era e tinha aquele funcionamento. Então a lei parte de muitas experiências concretas que a gente tentou, nos vários municípios onde a gente tinha uma atuação direta.

(...)

E.: Mas lembra o nome desse filme pra gente depois...

Amelinha: Ah, eu não consigo...

E.: Porque o sonho era...

Amelinha: Então, esse lugar seria um lugar ideal, você entendeu? Um lugar bonito, as mulheres teriam um acolhimento para elas pensarem, sabe? Para você atender bem essas mulheres você tem que ter tempo, filho, tempo. Eu já sentei com muita mulher de ficar o dia inteiro conversando com elas porque é tempo. Você chega com a cabeça cheia de problema ali, aquela coisa, sabe? Até você limpar aquilo ali tem que falar muito para poder limpar o negócio dela. É uma história que você consiga ter um desfecho, um caminho bom, é muito difícil. Então isso tudo eu falo por causa da lei, a lei não é nada disso, mas a gente tem que aquele sonho maior, né? Sonho maior. (grifos meus)

Esses três trechos da entrevista tocam em problemas centrais para a teoria do direito, para a discussão sobre a efetivação das políticas previstas na Lei Maria da Penha e para a reflexão sobre o problema da emancipação das mulheres. Como dissemos acima, Amelinha discute as delegacias de polícia como mecanismos de acolhimento, de escuta dos problemas relacionados à violência contra a mulher. Contrapõe à realidade das delegacias outro modelo de instituição corporificado no "sonho maior" de uma casa capaz de receber as mulheres de maneira mais afetiva $e$ oferecer um tratamento integral a seus problemas, para além da 
questão estritamente criminal, adequado para que ela supere sua situação de sujeição.

São colocadas lado a lado duas formas institucionais distintas, cada uma delas marcada por uma gramática diferente $e$ por uma racionalidade diferente, a começar por sua estrutura física. Na delegacia, a mulher precisa ir "lá na frente" no balcão, $e$ falar de problemas íntimos perante estranhos e/ou estranhas. $\mathrm{O}$ pior de tudo: normalmente, ela será atendida por um funcionário homem sem treinamento ou sensibilidade para lidar com o problema da violência contra a mulher. Já na "casa dos sonhos", na visão de Amelinha, a mulher seria recebida em um ambiente privado, afetivo, preocupado com seu bem estar físico $e$, principalmente, seria atendida sem pressa.

O funcionário ou funcionária da delegacia de polícia é retratado por ela como alguém pouco interessado nos problemas que se apresentam diante dele; um burocrata cujo objetivo principal parece ser livrar-se do trabalho sempre que isso seja possível. Por essa razão, ainda de acordo com o relato de Amelinha, esse funcionário desqualifica os relatos de violência contra a mulher e procura encaminhar a vítima a outros órgãos do Estado. $\mathrm{Na}$ "casa dos sonhos", ao contrário, o indivíduo será ouvido e levado em conta em sua singularidade. $\mathrm{O}$ atendimento deve ser pensado em função do relato de sua história; uma história que deve ser ouvida sem pressa em instalações físicas adequadas para esse fim.

As falas de Amelinha evidenciam uma visão muito clara da diversidade de formas institucionais em sua capacidade de figurar os problemas sociais ao escutar as vítimas da violência de maneira completamente diferente. Do ponto de vista dos debates atuais da teoria do direito, estamos aqui um passo além do debate tradicional sobre a juridificação das relações sociais.

Afinal, de acordo com Amelinha, não se trata de discutir se a regulação estatal é boa ou ruim vis a vis a possibilidade de gestão autônoma dos problemas pela sociedade. Ela não toca nessa questão. O que está em jogo aqui são, por assim dizer, duas estratégias de juridificação diferentes, duas maneiras diferentes de 
regular e lidar com o problema da violência contra as mulheres; uma delas considerada inadequado e o outro adequada tendo em vista sua capacidade de figurar corretamente o problema que se coloca diante dele. ${ }^{2}$

É provável que o modelo da delegacia possa ser adequado para lidar com outro tipo de problema social. A fala de Amelinha parece não condenar as delegacias em abstrato. No entanto, ela reflete sobre a incapacidade desses órgãos de lidar com um tipo de problema que, de acordo com ela, exige sensibilidade, pois gera vergonha e retraimento nas vítimas, além de demandar um atendimento que envolva múltiplos aspectos, financeiros, criminais, emocionais entre outros.

Fica claro aqui que a maneira pela qual se desenham as instituições deve guardar alguma relação com as questões sociais que ela irá enfrentar. A mera transformação da violência contra a mulher em crime, de acordo do Amelinha, parece ser incapaz de atender às necessidades efetivas do problema da violência. Dá-se a entender que o crime $e$ as instituições destinadas à persecução penal não figuram de maneira adequada às questões postas pela violência contra a mulher.

Mas é preciso deixar claro que esse argumento pode ser lido de duas maneiras diferentes. Em primeiro lugar, ele pode levar à conclusão de que a violência contra a mulher, em razão de suas características, não deve ser regulada por meio do direito penal. Ela deve ser objeto de outras formas institucionais que não funcionem de acordo com a lógica binária dos crimes e das penas; do criminoso e da vítima. De outra parte, tal argumento pode ser

2 A bibliografia sobre juridificação é imensa. Para uma visão relativamente completa da bibliografia mais importante sobre o tema até os anos 90, ver: Friedman, 1999. Outra referência importante é a obra de Jürgen Habermas. Na Teoria do Agir Comunicativo (1981), este autor via a regulação pelo direito como algo eminentemente negativo por suprimir a autonomia da sociedade para lidar com seus problemas em favor de uma gestão estatal, burocratizada. Já em Direito e Democracia (1992), essa visão do direito se altera. Habermas passa a pensar o direito como ambíguo, passível de disputa pela sociedade, ou seja, passível de construir modelos de juridificação mais ou menos democráticos. 
lido como um ataque radical à racionalidade penal como um todo. Com efeito, parece não haver argumentos razoáveis para que qualquer outro crime, seja ele contra o patrimônio ou contra a vida, não deva ser compreendido no contexto de uma série de outros problemas sociais, tão complexos quanto a violência contra a mulher.

Por exemplo ${ }^{3}$, apenas para levar o raciocínio ao extremo, uma pessoa que furta um tênis não está inserida em uma sociedade consumista que a trata como objeto - e que trata a todos como meros objetos - de modo a fazer a sua autoestima depender da posse de um tênis de marca? Posto isso, tratar esse fato como um crime não significa ocultar o que ele tem de mais essencial em favor da lógica binária do criminoso e de vítima? Nessa mesma ordem de razões, não seria razoável considerar que o direito penal como um todo é, por assim dizer, uma patologia regulatória que deve ser combatida e evitada porque tem como efeito principal ocultar aquilo que os problemas sociais possuem de mais característico?

A despeito de minha simpatia pessoal por esta posição, é importante fazer aqui uma distinção, crucial para aclarar os termos do problema com o qual estamos lidando. Uma coisa é debater, em abstrato, a racionalidade penal e seus supostos efeitos deletérios. Esse é um debate propriamente utópico que se dá descolado de qualquer contexto, das opções políticas enfrentadas pelos agentes sociais reais e do significado social que cada alternativa adquiriu no processo de luta por direitos (Rodriguez, 2013, 2015). Essa espécie de pensamento utópico parte do pressuposto de que seria possível escolher entre alternativas institucionais as mais variadas em abstrato, dispostas na forma de um "cardápio institucional" que desconsidera o enraizamento social das instituições.

Coisa muito diferente é debater as estratégias regulatórias postas na mesa, ou seja, debater a partir do ponto de vista dos atores sociais reais e suas alternativas no contexto dos embates

3 Agradeço a Marcella Beraldo pela sugestão do argumento . 
306 "Utopias" institucionais antidiscriminação

que enfrentam e das instituições como elas existem atualmente, como ilustra muito bem a fala de Amelinha e seu sonho maior nada utópico.

É fácil compreender porque Marx se irritava tanto com os simpáticos, mas potencialmente deletérios, pensadores utópicos (Marx, 2009). Afinal, esse modo de pensar não contribui em nada para a compreensão dos dilemas da luta social real. A utopia pode eventualmente ser útil para ampliar o repertório das alternativas pensadas em abstrato. No entanto, ela não diz nada sobre as reais escolhas possíveis, encarnadas em um determinado contexto de luta por direitos.

Por isso mesmo, um pensador utópico, mesmo que à revelia de suas melhores intenções, pode terminar por desrespeitar os agentes sociais reais. Seu modo de pensar e agir pode dar a entender que determinado agente social não é "radical o suficiente", pois não consegue "pensar o impossível" passando por cima de suas necessidades e possibilidades reais.

De um ponto de vista não utópico, não consigo identificar razões convincentes para afastar a estratégia penal do problema da violência contra a mulher. Estamos diante de um fato social complexo como qualquer outro, um problema que envolve mais mediações e nuances do que a lógica binária do direito penal é capaz de figurar. A não ser que se imagine ser possível pensar o direito penal para além das ideias de crime e de pena. Mas essa já seria outra discussão. ${ }^{4}$

Seja como for, defender a suposta especificidade da questão da violência contra a mulher para afastar o direito penal de sua regulação pode resultar no efeito indesejado e conservador de

4 Pensando livremente sobre essa possibilidade, tenho dúvidas sobre sua viabilidade. Classificar como penais mecanismos regulatórios que não incluam "crimes" e "penas" em sua lógica de funcionamento ou que não estejam majoritariamente relacionados com esses institutos jurídicos torna a expressão inútil ou complexa a ponto de inviabilizar a comunicação. Nesse sentido, partindo do pressuposto de que os problemas sociais são sempre complexos $e$ cheios de nuances, todo "reformismo penal" seria contraproducente. A única resposta emancipatória coerente seria o abolicionismo penal. 
remeter o problema de volta à esfera privada, como veremos adiante.

Para retomar o fio da exposição, em outro momento da entrevista, Amelinha menciona que a preocupação do movimento feminista com a esfera penal, em seu entender, era secundária. No centro de suas preocupações estava a discussão sobre o problema da mulher e as diversas dimensões que ele encerra; problema que não pode ser solucionado apenas pela esfera penal. A principal demanda do movimento, ainda segundo o relato de Amelinha, sempre foi a construção de algo parecido com a "casa dos sonhos", encarnada em parte, por exemplo, no projeto da Casa Eliane de Grammont criada durante a Prefeitura de Luiza Erundina, na Cidade de São Paulo.

Percebe-se aqui também como Amelinha pensa a luta feminista, entre outras coisas, como uma luta por determinados modelos de juridificação, uma luta por determinados modelos institucionais, por um determinado desenho do Estado em sua relação com a sociedade. Um de seus objetivos parece ser refletir sobre as instituições e imaginar formas institucionais, "utopias" institucionais, por assim dizer, mais adequadas para lidar com os problemas das mulheres.

Escrevo utopia entre aspas, pois, na verdade, esse modo de pensar guarda pouca coisa de utópico. Trata-se de encarar o "direito", as "instituições", o "Estado" como alguma coisa de plástico, alterável, dialógico, em disputa, passível de construção e reconstrução e não como algo engessado, rígido, imóvel $e$ unilateral. Nesse sentido, "juridicizar" as relações sociais pode significar muitas coisas, pode envolver várias estratégias de políticas públicas, vários desenhos institucionais, inclusive aquele que venha tratar o problema de maneira adequada e que ainda precisam ser inventados.

Vai ficando claro que o "Estado de direito" não se resume às delegacias de polícia, aos tribunais, às leis $e$ aos direitos $e$ deveres que elas protegem. Há mais possibilidades institucionais no interior dessa gramática; possibilidades que passam longe do mundo dos crimes e das penas sem deixar de se caracterizar como 
instituições formais do Estado de direito. Afinal, a "casa dos sonhos", se chegar a ser criada de fato, deverá ser gerida por funcionários públicos sob um regime legal, fará suas contratações e compras sob o regime do direito administrativo, exercerá seu afeto e sua escuta atenta regulada por leis, regulamentos e outros tipos de norma jurídica.

\title{
Violência e gênero: o papel do Estado e seus limites
}

A literatura sobre a Lei Maria da Penha tem discutido de maneira recorrente as questões abordadas por Amelinha em sua entrevista. Por exemplo, na abertura de um dos textos centrais desse campo de pesquisas, escrito por Guita Grin Debert e Maria Filomena Gregori, encontramos a seguinte reflexão sobre a juridificação:

\begin{abstract}
Alguns analistas consideram que essa expansão do direito e de suas instituições ameaça a cidadania e dissolve a cultura cívica, na medida em que tende a substituir o ideal de uma democracia de cidadãos ativos por um ordenamento de juristas que, arrogando-se a condição de depositários da ideia do justo, acabam por usurpar a soberania popular. As delegacias especiais de polícia voltadas para a defesa de minorias são, no entanto, fruto de reivindicações de movimentos sociais e, por isso, podem ser vistas como exemplo que contesta tal argumentação. Elas indicam antes um avanço da agenda igualitária, porque expressam uma intervenção da esfera política capaz de traduzir em direitos os interesses de grupos sujeitos ao estatuto de dependência pessoal (Debert e Gregori, 2007:166).
\end{abstract}

De modo semelhante ao que diz Amelinha, as autoras tomam a intervenção do Estado sobre a questão da violência como passível de disputa, não como algo necessariamente negativo. $\mathrm{O}$ texto segue para afirmar logo em adiante, citando Habermas, que o "sistema de direitos pode ser atualizado democraticamente" (Debert e Gregori, 2007:166), ele não é, necessariamente, um instrumento para suprimir a autonomia da 
sociedade. Nesse sentido, é preciso compreender, segundo as autoras, as negociações e disputas que ocorrem no âmbito da justiça para avaliar as possibilidades e limites do direito, no que interessa mais de perto a elas, as delegacias de polícia e os juizados especiais, principais órgãos do Estado responsáveis por combater a violência contra a mulher.

Débora Alves Maciel, por sua vez, avalia a campanha da Lei Maria da Penha também no contexto de mobilização social, tendo em vista a criação de direitos por meio dos tribunais e criação de instituições estatais, especialmente penais. A autora afirma que prevalece na literatura brasileira sobre a mobilização coletiva das normas $e$ instituições jurídicas a noção de "judicialização da política" que exclui a análise do papel do direito nos processos de conflito e mobilização (Maciel, 2011:99).

Esse modo de ver o problema, ainda de acordo com a autora, aqui parafraseando texto de Andrei Koerner, fica
circunscrito ao problema da legitimidade formal do poder governamental, dos possíveis efeitos da ampliação do poder judicial sobre a relação entre os poderes e a tensão potencial entre princípios típico-ideais de legitimidade decisória dos sistemas democráticos, o majoritário e o judicial (Maciel, 2011:99). ${ }^{5}$

Ainda de acordo com Maciel, a agenda de pesquisa construída sob a égide do paradigma da "judicialização da política":

... deixa à margem questões relevantes sobre o próprio processo de mobilização dos tribunais; quando, como e por que o direito e suas instituições se convertem em recurso $e$ estratégia de ação política? Com qual intensidade e de que modo os agentes elegem, no decurso das disputas, uma ou outra das diferentes esferas do poder governamental, Judiciário, Executivo e legislativo? (Maciel, 2011:99)

\footnotetext{
${ }^{5}$ Sobre esse ponto, Nobre e Rodriguez (2011) afirmam que a agenda da judicialização da política tende a naturalizar as instituições em seu estado atual, em especial a separação de poderes, assumindo significado conservador.
} 
É justamente essa agenda, a maneira pela qual o direito está sendo disputado pelas forças sociais e administrado pelos agentes do Estado, que tem ocupado boa parte da pesquisa empírica sobre a violência contra a mulher nos últimos anos. Lourdes Bandeira identifica como um dos problemas centrais para a efetivação da Lei Maria da Penha a "mudança nos paradigmas disciplinares no campo jurídico de formação universitária $e$ profissional" (Bandeira, 2009:424) que têm impacto sobre a atuação dos organismos do Estado.

Logo a seguir, a autora cita estudos de sua autoria que apontam para a "ideologia de conciliação" do Judiciário. De acordo com a autora, esse poder tende a devolver o problema da violência contra a mulher para o âmbito privado, eximindo o poder público de intervir sobre aquela situação, tudo em razão de uma racionalidade "familista" que coloca em primeiro plano a necessidade de promover a harmonia familiar (Bandeira, 2009:427 e 429).

Esses mesmos problemas são abordados por Guita Grin Debert e Marcella Beraldo de Oliveira (2007) em texto que compara a atuação das Delegacias da Mulher com os Juizados Especiais Criminais na cidade de Campinas $e$ incorpora os principais resultados da dissertação de mestrado de Beraldo de Oliveira, citada no trabalho. $\mathrm{O}$ artigo mostra como os juízes e juízas tendem a buscar conciliar o casal, muitas vezes assumindo uma postura paternalista e moralizante que procura "corrigir" $\mathrm{O}$ homem e "melhorar" a relação entre os dois.

Essa postura não toca na questão da assimetria de pode entre os gêneros e termina por reafirmar a superioridade do homem em relação à mulher ao deixar a situação no estado em que se encontra por meio da oferta de conselhos sobre como conviver bem e/ou pela tentativa de promover a conciliação do casal com a aplicação de medidas alternativas, substitutivas da sanção criminal, como a entrega de um ramalhete de flores para a "companheira" (Debert e Beraldo, 2007).

Seja como for, a literatura que trata do tema parece considerar superada a discussão sobre a "juridificação" das 
relações sociais, focando sua atenção sobre a qualidade das instituições do Estado e seus limites, ou seja, sobre os instrumentos escolhidos pelo Estado para lidar com o problema da violência contra a mulher e seus efeitos práticos; sua capacidade de dar conta de todos os aspectos da questão.

Nesse sentido, Cortizo e Goyeneche, em uma breve síntese dessa literatura, mostram o perigo de simplificação que a criminalização da violência traz em seu bojo ao deixar de lado a complexidade do fenômeno da violência; em especial, ao não se preocupar com o trabalho psicossocial a ser realizado com os agressores e pensar a vítima em uma posição meramente passiva e sem poder de decisão (Cortizo e Goyeneche, 2010:106-107).

No livro Fuga do Direito, de minha autoria, proponho o conceito de "modelo de juridificação" para dar conta desse tipo de discussão (Rodriguez, 2009). Com efeito, cada modelo de juridificação implica em uma determinada maneira de conceber $e$ regular a relação entre Estado e sociedade, ou seja, implica em desenhos institucionais diferentes que ajudam a construir uma determinada "gramática" destinada a figurar as demandas sociais pelas instituições formais. ${ }^{6} \mathrm{O}$ direito não é algo pelo qual a demanda social "passa", mas se torna constitutivo dela.

Nesse sentido, a fala de Amelinha sobre a forma de acolher e ouvir as demandas nas delegacias de polícia e na "casa dos sonhos" ilustra com clareza essa problemática, em especial os limites do direito penal para lidar com a violência contra a mulher. É ocioso buscar o que seja "a sociedade" "fora" dos limites do Estado de direito. Algo supostamente "espontâneo" e "puro".

\footnotetext{
6 No último capítulo do livro mencionado acima, Fuga do Direito, eu afirmo que o Estado de direito dispõe de duas gramáticas básicas para lidar com os problemas sociais: a "gramática normativa" e a "gramática da autorregulação" ou, em uma formulação mais recente (Rodriguez, 2014), a gramática da "regulação estatal" e a gramática da "regulação social". A primeira utiliza normas criadas pelo Estado para regular as condutas - normas essas que são aplicadas por tribunais e outros organismos estatais. Já a gramática da regulação social atribui a instituições não estatais competência para criar (e eventualmente administrar e aplicar) normas jurídicas que regulam os problemas sociais.
} 
O necessário avanço da juridificação nesse caso, que ajudou a tornar pública a questão da violência, antigamente relegada à intimidade ("em briga de marido e mulher ninguém põe a colher"), precisa ser discutido em função de vários modelos de juridificação e de sua gestão democrática, não de uma eventual "retração" do Estado de direito em favor de uma suposta "autonomia" dos particulares.

A exemplo do mercado capitalista, que deixado a si mesmo produz monopólios e desigualdade social pela exploração extrema do trabalho, as relações afetivas, deixadas a si mesmas, parecem produzir posições assimétricas de poder, exploração do corpo da mulher, discriminações de gênero de naturezas as mais diversas, ou seja, violência. Por isso mesmo, autonomia não pode significar desregulação, mas regulação no sentido da emancipação.

Em suma, no que diz respeito aos problemas relacionados ao atual modelo de juridificação adotado pelo Brasil para lidar com a violência contra a mulher, a literatura parece gravitar em torno de três questões principais. Primeiro, parece haver clareza sobre o caráter parcial do processo de juridificação que, a despeito de necessário para empoderar as mulheres por tirar a questão da violência do âmbito meramente privado $^{7}$, deixa de lado outras formas possíveis de solucionar o conflito, eventualmente não estatais, mas igualmente jurídicas. Segundo, a via escolhida pela Lei Maria da Penha, o direito penal, é visto como uma estratégia problemática que apresenta limites muito claros, como será visto adiante.

Terceiro, a literatura mostra também, como vimos acima, que os agentes estatais têm um papel crucial na administração da justiça e na interpretação das normas e precisam ser objeto de análise específica.

Nesse sentido, Maciel afirma que a partir de 2007 se inicia um novo ciclo de mobilização do movimento feminista. Nesse ano foi criado o Observatório Nacional de Implementação e Aplicação

7 Sobre esse ponto, que não vou aprofundar aqui, veja-se Femicídio: algemas (in) visíveis do público-privado de Suely de Almeida (1998). 
da Lei Maria da Penha que se juntou aos Planos Nacionais de Políticas para as Mulheres, elaborados a partir de 2004. Essa fase é caracterizada pela reflexão e atuação sobre o Judiciário, objeto de lobby para a aplicação da lei. Na fase anterior o alvo central o Poder Legislativo, pois o objetivo era o de promover a aprovação da Lei Maria da Penha (Maciel, 2011:103-104). ${ }^{8}$

\section{Responsabilização, "familismo" e misoginia}

A reflexão sobre a atuação do Judiciário e sobre a juridificação da violência em geral se desdobra em vários aspectos. Na bela síntese de Lilia Guimarães Pougy (2010), um dos problemas centrais do modelo judicial e penal é o fato de que ele trata como individual uma questão estrutural, sistêmica $e$ relacional. Ao fazer um breve estado da arte da literatura sobre o tema, a autora mostra, citando diversos estudos sobre o assunto, que é preciso combater a "cultura vitimista" que vê a mulher isolada e fragilizada, vítima de um ato de violência sem levar em conta a hierarquia entre os gêneros, consubstanciada em diversas dimensões das relações sociais, inclusive as relações conjugais.

A autora esclarece, citando estudo clássico de Gregori sobre a "lógica da queixa", ao qual voltaremos adiante (Gregori, 1993), que a opressão à mulher não se altera apenas com intervenções voltadas à sua consciência: é preciso focar a interação entre homens e mulheres, o lugar social em que os sujeitos se encontram $e$ as representações que orientam suas ações (Pougy, 2010:78).

No que se refere especificamente à violência no âmbito doméstico, como já discutimos no item anterior deste texto, a individualização do conflito é particularmente cruel ao deixar de lado a imensa dificuldade das mulheres de romperem o ciclo de violência em razão de sua fragilidade econômica, dos laços sentimentais que as mantêm ligadas aos seus supostos companheiros, entre outros problemas. Por essas razões, a

8 Sobre esse assunto, ver o texto: Machado, Rodriguez et al., 2012. 
violência doméstica já foi comparada com as práticas de "tortura" e "terrorismo" pelos estudiosos do assunto para dar destaque à dificuldade de romper definitivamente os laços que ligam vítima e agressor (Almeida, 1998).

Outro problema central do modelo de juridificação adotado pela Lei Maria da Penha é sua ligação muito estreita com a proteção à família, presente já no título da lei, que prevê medidas para combater a violência doméstica e familiar. Debert e Gregori afirmam que a aprovação da lei nesses termos se explica em parte pelo fato de que esse tipo de violência, a doméstica, é aquele que gera mais indignação na sociedade.

A ideia de que a violência contra a mulher não se reduz ao espancamento de esposas e companheiras é um princípio básico do discurso das feministas que se manifestaram contra a criação das Delegacias de Polícia de Proteção à Mulher ou a seu favor. Mas são essas expressões que mobilizam a maior indignação e por isso, apesar das ênfases dos militantes de não reduzir os problemas à dimensão familiar, a violência doméstica aparece como uma expressão englobadora das mazelas da sociedade brasileira e passa a ser confundida e usada como sinônimo de violência contra a mulher, da violência contra a criança ou ainda da violência contra o idoso (Debert e Gregori, 2008:170).

Esse "deslocamento semântico", ainda de acordo com as autoras, desloca a discussão das assimetrias de poder entre os gêneros nas mais diversas relações sociais para o âmbito familiar com o risco de diluir a violência de gênero nas políticas de proteção à família. A observação etnográfica do atendimento concreto às mulheres mostra que a violência, nesse enfoque, tende a ser tratada como características de famílias desestruturadas, carentes de educação ou tradicionais (Debert e Gregori, 2008:170). ${ }^{9}$

\footnotetext{
9 As autoras não investigam expressamente no texto a razão dessa indignação exacerbada que parece se dever, justamente, à aproximação entre violência contra a mulher e proteção da família - tema que guarda forte apelo para grupos
} 
Essa moralização do problema detectada, por exemplo, nos Juizados Especiais Criminais de Campinas, pode resultar, no limite, na frustração completa dos objetivos de combater a assimetria do poder entre gêneros na sociedade. Desse modo, o conflito moralizado é remetido de volta ao âmbito privado:

A vítima, de sujeito de direitos é constituída em esposa ou companheira; da mesma forma que o agressor passa a ser marido ou companheiro. O crime se transforma em um problema social ou num déficit de caráter moral dos envolvidos que, na visão da justiça, pode ser facilmente corrigido através de esclarecimentos e nos casos mais difíceis pode ser compensando por uma pequena pena. A lógica que orienta a conciliação nos juizados implica em uma solução rápida, simples, informal e econômica para os casos que não deveriam estar ocupando espaço no Judiciário tampouco o tempo de seus agentes (Debert $e$ Beraldo, 2007:172).

Como explica Lourdes Bandeira, os crimes contra a mulher são "crimes de poder" que implicam no "controle viril do corpo feminino" e têm como causas "a banalização e a incorporação do uso sistemático da violência para a resolução de conflitos cotidianos, as diversas situações de hierarquias que permeiam as relações de afetividade" (Bandeira, 2009:406).

Conforme atestado pela natureza das relações interpessoais e sociais existentes, testemunhadas nas comunidades

religiosos e grupos conservadores. Proteger a mulher das assimetrias de poder "no seio da família" é um objetivo muito diferente daquele de combater o problema da violência de gênero na sociedade como um todo; essa, uma pauta que encontra mais dificuldade em ser abraçada pela esfera pública porque inclui questões relativas a mulheres que não se beneficiam da imagem de "mãe"; além de gays, lésbicas, transgêneros, travestis e outras manifestações de gênero. A proteção da violência contra a mulher em função da família pode ter sido uma boa estratégia política para fazer avançar a questão no Legislativo, mas de outro lado, criou o "deslocamento semântico" mencionado, o qual, diga-se, parece ser mais político do que meramente semântico. 
316 "Utopias" institucionais antidiscriminação

masculinas de origem, fragmentos de depoimentos colhidos em pesquisas etnográficas ilustram os argumentos usados pelos agressores-assassinos e seus advogados-defensores: "matei por amor, zelo..."; "matei porque a queria demais..."; "matei para preservá-la da maledicência alheia..."; "matei porque estava fora de mim..."; "fiquei louco de ciúmes, não sabia o que estava fazendo..."; "matei para defender minha honra..." (Bandeira, 2009:406).

A valorização da família tem sido acompanhada, de acordo com Debert e Gregori, por uma revalorização de uma suposta liberdade de escolha das mulheres. Nesse registro, a violência se transforma em uma questão de "falta de confiança", de "autoestima" ou em um problema de comunicação entre o casal, que poderiam ser resolvidas por meio do diálogo (Debert e Gregori, 2007:173).

Essa tendência, segundo as autoras, pode ser situada num contexto mais geral de reflexão sobre as instituições em que os tribunais não seriam mais responsáveis pela segurança. Nesse registro ideológico, são necessárias uma reforma moral e uma reconstrução ética dos envolvidos na criminalidade para que as questões sejam resolvidas:

Isso abre espaço para um amplo espectro de técnicas psicológicas recicladas em programas para governar os excluídos, que atuam com os juízes de modo a aprimorar a aplicação de mecanismos de mediação de conflitos. Neles, o pressuposto da escolha ética é central, a relação que o indivíduo estabelece consigo mesmo é o alvo dos profissionais e o trabalho a ser feito em associação com os diferentes especialistas é o de preparação dos indivíduos para se tornarem livres (Debert e Gregori, 2007:175).

Tal estado de coisas levou Debert e Gregori a se perguntarem se o pensamento penal crítico não seria majoritariamente misógino, citando como evidência disso estudo 
de Carmen Hein de Campos sobre o assunto (Campos, 2007). ${ }^{10}$ Afinal, a condenação da criminalização da violência contra a mulher, tout court, sem uma alternativa clara que não promova sua desregulação e sua privatização, poderia ter como efeito, no momento atual, devolver o problema definitivamente à esfera privada. $\mathrm{O}$ pensamento utópico antipenal, nesse caso, pode ter claros efeitos conservadores.

De fato, talvez seja esse um dos problemas ao qual o poder simbólico da categoria "crime" tenha prestado melhores serviços à emancipação da mulher, a despeito das críticas que se possa fazer ao excesso de criminalização dos fatos sociais como um todo, e da necessidade de construir outros instrumentos para lidar com a questão para além do aparato criminal.

Por exemplo, Rodrigo Ghiringhelli de Azevedo lamenta que a Lei Maria da Penha tenha acabado com a possibilidade de conciliação entre as partes, oportunidade em que poderiam discutir seu conflito e serem informadas sobre as consequências de seus atos. Azevedo critica a defesa sem reflexão da detenção dos agressores a qual, segundo ele, tem pouca eficácia em resolver o problema, além de estigmatizar o agressor.

$\mathrm{Na}$ opinião do autor, a melhor forma de combater a violência seriam as medidas não penais previstas pela Lei Maria da Penha, que incluem a criação de Centros de Referência com

\footnotetext{
${ }^{10}$ Esse questionamento poderia ser estendido para outros setores do direito, digase, em especial para o direito de família e o direito do trabalho, para citar apenas dois exemplos. Por exemplo, uma pesquisa de 2008 mostrou que os tribunais trabalhistas praticamente não examinavam nenhum caso de discriminação contra as mulheres ou assédio sexual. Certamente isso não se devia (os dados foram colhidos em 2008) à inexistência de fatos que pudessem ser enquadrados dessa forma na legislação, mas a obstáculos a sua identificação e ao processamento pelo direito do trabalho. A pesquisa levanta a hipótese, tendo em vista a legislação espanhola, que a criação de comitês internos nas empresas para receber denúncias de discriminação poderia funcionar para relativizar a hierarquia que marca as relações de trabalho, hierarquia que, combinada com a possibilidade de demissão sem justificativa presente em nossa legislação, dificulta a qualquer pessoa propor uma ação judicial no curso da relação de emprego (Rodriguez e Nobre, 2009).
} 
atendimento multidisciplinar (Azevedo, 2008:127-130). Ou seja, a melhor solução seria pensar na juridificação para além do direito penal sem, no entanto, acrescentaria eu, correr o risco de devolver a questão ao mundo privado, ou seja, ao domínio da assimetria de poder entre os gêneros.

Para evitar este desfecho, parece importante admitir claramente a admitir a hipótese de que o sistema penal possa funcionar ao lado de outros mecanismos de acolhimento, ao lado de outro tipo de instituição, cuja lógica não seja aquela dos crimes $e$ das penas. Novamente, a crítica ao penal sem uma alternativa institucional real pode provocar efeitos conservadores. $\mathrm{O}$ inimigo maior aqui parece ser não o direito penal, mas um pensamento utópico que reduza todas as opções na mesa em escolhas igualmente ruins.

\section{Uma "utopia" feita de papel?}

Com efeito, quanto a esse ponto, a literatura ressalta a importância de se tratar a violência como problema relacional, estrutural, complexo. Menciona-se a necessidade de construir mecanismos adequados para lidar com suas várias dimensões, em especial, a assimetria de poder entre os gêneros. No entanto, nesse ponto os textos e a fala de Amelinha tornam-se imprecisos e vagos. Não há clareza sobre que medidas seriam as mais adequadas para lidar com a violência de gênero, não há alternativas claras postas na mesa para além da alternativa penal vigente.

Tal estado de coisas parece estar provocando outro deslocamento político-semântico de consequências negativas sobre a disciplina do problema: a identificação do direito, da gramática do Estado de Direito, com a gramática dos crimes e das penas; a gramática das leis, dos tribunais, das delegacias, dos juízes, dos advogados, promotores e de uma narrativa que busca de um "responsável" individual que deve sofrer consequências jurídicas negativas. 
Nesse sentido, o desafio parece ser agora institucionalizar os organismos e as políticas mencionadas pela Lei Maria da Penha, ou seja, criar e manter em funcionamento mecanismos que permitam construir, em função de sua estrutura, inclusive de sua configuração física, outras narrativas sobre a violência de gênero. É disso que trata a lei a afirmar que os Centros de Referência devam oferecer um "atendimento multidisciplinar" capaz de acolher e constituir outras narrativas dos problemas que irão enfrentar. ${ }^{11}$

Afinal, como observou Amelinha, a mulher precisa "ir lá na frente" em uma delegacia, porque o que importa nesse caso são as informações sobre o crime, o nome do agressor $e$ as circunstâncias do fato supostamente criminoso. Para os fins do direito criminal, ficam abstraídas as questões relativas às emoções da vítima, suas dificuldades para romper o ciclo de violência e ter coragem para ir até a delegacia. O direito penal não foi construído para lidar com esses problemas. O corpo da vítima e suas circunstâncias são menos importantes do que aquilo ela irá dizer, do que a notícia do crime. E para esse objetivo, um balcão "lá na frente" é mais do que adequado.

Em suma, ficar apenas com o direito penal parece ser insuficiente, mas abrir mão dele pode ter efeitos conservadores.

\footnotetext{
${ }^{11}$ A tentativa politicamente equivocada de Foucault de valorizar a "justiça popular" em seu debate com os maoístas parece-me motivada por boas razões: encontrar um modelo de jurisdição cuja narrativa não seja individualizante $e$ culpabilizadora (Foucault, 1979). Em seu texto sobre o "hate speech", Judith Butler toca no mesmo problema ao mostrar como a individualização do racismo pelas decisões judiciais pode levar a resultados pouco adequados ao tocar no que a questão tem de mais essencial (Butler, 1997). Robert Cover explorou as características da narrativa tradicional do direito em textos geniais, mas ainda pouco lidos ao redor do mundo (Cover, 1995). O livro recente de Luc Boltanski, mais do que um estudo sobre os romances policiais (Boltanski, 2012), aborda o momento histórico que deu centralidade a uma forma narrativa que caracteriza o direito penal contemporâneo e influencia o desenho das instituições jurídicas em vários campos, como mostra Klaus Günther em texto crucial para compreender o direito contemporâneo (Günther, 2002).
} 
320 "Utopias" institucionais antidiscriminação

Seja como for, Cortizo e Goyeneche mostram que tais instituições e políticas previstas pela lei ainda não foram criadas ou estão sendo criadas de forma desigual ao redor do país (Cortizo e Goyeneche, 2010:108). A lei exige que os Centros de Referência sejam:

... espaços de acolhimento/atendimento psicológico, social, orientação e encaminhamento jurídico à mulher em situação de violência, que proporcionem o atendimento $e$ o acolhimento necessários à superação da situação de violência ocorrida, contribuindo para o fortalecimento da mulher e o resgate da sua cidadania.

... devem exercer o papel de articulador das instituições $e$ serviços governamentais e não governamentais que integram a Rede de Atendimento, [...]

... devem prestar acolhimento permanente às mulheres que necessitem de atendimento, monitorando e acompanhando as ações [...] (Brasil, 2006:15).

O atendimento multidisciplinar deve "ser integrado por profissionais especializados nas áreas psicossocial, jurídica e de saúde" (Brasil, 2006, Art. 29 e 60) e:

... fornecer subsídios por escrito ao Juiz, ao Ministério Público e à Defensoria Pública, mediante laudos ou verbalmente em audiência, e desenvolver trabalhos de orientação, encaminhamento, prevenção e outras medidas, voltadas para a ofendida, o agressor e os familiares, com especial atenção às crianças e aos adolescentes.

Com efeito, a formulação genérica e abstrata do que devam ser os Centros de Referência no texto da Lei Maria da Penha parece estar à altura da utopia institucional - a "casa dos sonhos" imaginada por Amelinha Telles. Resta saber se a implantação desses organismos $e$ as políticas levadas adiante por eles ficarão relegada apenas à letra da lei. 
Mas para que isso seja possível, diante dos obstáculos a que este texto faz menção, parece ser necessária uma mobilização política com força renovada para que sejam destinados recursos do Estado para tal fim, ou seja, para que o combate à violência deixe de ser sinônimo de punir os agressores pela via penal.

A realização desse objetivo exige que se desvincule "criminalização" e "juridificação" no debate público, abrindo um espaço maior para demandas dirigidas à efetivação da lei diferentes de sua dimensão criminal. Novamente, o texto de Debert e Gregori dá conta do problema ao propor a diferenciação clara, no contexto dos embates contemporâneos, entre "violência" e "crime" (Debert e Gregori, 2007:176), diferenciação essa que parece estar ainda distante em uma esfera pública dominada por demandas pela criminalização dos mais diversos problemas sociais (Azevedo, 2008).

No caso específico da violência contra a mulher, tal diferenciação é ainda mais importante. Afinal, parece evidente que existe uma afinidade eletiva entre o discurso da vitimização $e$ a forma do direito penal. E tal afinidade parece ter funcionado, a par da indignação da esfera pública, mencionada por Debert $e$ Gregori, como fator importante no processo de aprovação da Lei Maria da Penha pelo Congresso Nacional.

Pois se é verdade que a lei foi capaz de empoderar as mulheres ao tornar público um problema privado, ela o fez utilizando um modelo de juridificação que resulta em uma narrativa que individualiza o problema da violência e favorece o discurso da vitimização, ao colocar o homem no papel de "agressor", criminoso, e a mulher na condição de "vítima", ré, sem tocar as estruturas reproduzem a dissimetria de poder que caracteriza as relações de gênero. ${ }^{12}$

\footnotetext{
${ }^{12} \mathrm{O}$ debate sobre a possibilidade ou não de responsabilizar penalmente ou não as pessoas jurídicas é uma ilustração muito clara da "forma direito criminal". O problema aqui é a dificuldade de se encontrar um indivíduo "culpado" por uma eventual ação criminosa de uma determinada pessoa jurídica. A dificuldade se deve ao fato de que uma empresa, sociedade etc. pode ter um processo decisório
} 
Em seu estudo sobre o fracasso do SOS Mulher, serviço criado por militantes feministas na década de 80, Cenas e Queixas (1993), Maria Filomena Gregori deixa claro, em primeiro lugar, para lembrar a discussão acima sobre juridificação, que a criação de uma instituição em bases espontâneas, anárquicas $e$ voluntaristas, com um espírito profundamente "anti-institucional" $e$ que nunca se voltou para o Estado com o objetivo de buscar apoio para sua continuidade, produziu resultados constrangedores.

Gregori mostra como a atuação do SOS Mulher foi marcada pela profunda incompreensão das militantes sobre a realidade das mulheres atendidas, todas de classe social mais baixa ${ }^{13}$, além de uma falta de reflexão sofisticada sobre a dinâmica complexa e cheia de nuances de uma relação conjugal violenta, analisada na segunda parte do livro (Gregori, 1991).

De acordo com Gregori, as militantes acreditavam que a mudança seria resultado da conscientização das mulheres exclusivamente por meio do discurso; e que era necessário evitar toda e qualquer forma de hierarquia e de limitação à atuação livre de cada uma das pessoas envolvidas na atividade. A atuação do SOS partia do pressuposto de que havia uma experiência feminina universal que poderia ser despertada por meio do discurso; de uma conversa esclarecida que tinha como finalidade conscientizar as mulheres de sua condição de opressão.

Como resultado dessa postura, as mulheres atendidas nunca passavam da primeira visita ao SOS mulher, não havia padronização no atendimento, as fichas de atendimento eram incompletas e nunca foram catalogadas, cada militante dizia o que queria no limite de seu conhecimento, os casos não eram debatidos coletivamente, entre outros procedimentos de eficácia duvidosa (Gregori, 1991).

que envolva muitas pessoas, muitas instâncias, muitas fases, muitos atos encadeados e interdependentes. Para esse problema, ver: Machado, 2009.

${ }^{13}$ Gregori não cita esse texto, mas parecem ser relevantes para essa questão as análises de Sarti, 2012. 
Nesse sentido, é significativo que o SOS Mulher tenha fechado suas portas em uma reunião que culminou com uma fala que acusa as mulheres atendidas de não serem feministas, de irem até o SOS enviadas por deputados de direita e por agirem como verdadeiras cúmplices de seus agressores (Gregori, 1992:116-118). Essa fala, para mim, paradoxalmente, parece retratar as militantes como verdadeiras vítimas da falta de compreensão ideológica das mulheres que elas pretendiam ajudar a mudar de vida.

Além disso, e esse é o ponto que nos interessa mais de perto agora, a leitura do livro de Gregori parece deixar claro, que o discurso vitimizador tem uma afinidade clara com a forma narrativa que caracteriza o direito penal, ou seja, com a forma narrativa da jurisdição tradicional. A autora não afirma isso em seu livro, mas após ler a análise das entrevistas feitas por ela com diversas mulheres agredidas, fica evidente que a penalização parece ter sido a resposta institucional mais adequada para a demanda de uma política pública que vê a questão da violência a partir das figuras da "vítima" e do "agressor".

Ademais, ao ser consagrado na forma de uma lei que foi alçada à posição de emblema pelo movimento feminista contemporâneo, o discurso penal passa a ser reiterado e revestido do poder simbólico que o Estado de Direito tem o condão de conferir a todo programa ou projeto que seja transformado em lei e em decisão judicial. As categorias de "vítima" e "agressor" passam a ser, cada vez mais, reforçadas em sua legitimidade perante a esfera pública ${ }^{14}$, o que torna ainda mais difícil a separação política e conceitual entre "crime" e "violência".

Tal indistinção pode explicar em parte a falta de clareza da literatura que estudamos sobre a institucionalização dos

\footnotetext{
${ }^{14}$ Sobre o papel do direito na naturalização de categorias, ver Brown, 2002. Para uma discussão sobre o papel do Estado como centro de legitimação de discursos, sobre os perigos de abuso dessa instância legitimadora e os problemas que a relação com o Estado pode trazer para a ação dos movimentos sociais, ver Butler, 2003. Os dois textos fazem parte da coletânea Brown e Halley (2002), dedicada à reflexão sobre a relação entre os movimentos sociais e o direito, em especial o movimento feminista, no contexto norte-americano.
} 
organismos de natureza não penal previstos na Lei Maria da Penha. Apesar de esses textos discutirem os limites da forma penal, o debate na esfera pública e as políticas públicas do Estado brasileiro parecem estar ainda dominados pela dimensão penal da lei. Desfazer essa situação parece exigir, para pensar com Débora Alves Maciel (2001), uma nova fase de mobilização pela efetivação da Lei Maria da Penha por parte dos movimentos sociais. Afinal, os movimentos das categorias no discurso, os deslizamentos semânticos mencionados por esse texto não podem ser apartados do movimento das lutas sociais.

No entanto, é preciso ressaltar que as análises de Gregori (1994) também nos levam a desconfiar que a efetivação do aparato não penal da Lei Maria da Penha pode não ser suficiente para superar a visão da violência contra a mulher como uma relação entre agressor e vítima. No SOS Mulher, o atendimento se propunha a escapar da lógica penal, no entanto, não deixava de lado a ideologia da vitimização, a qual foi em grande parte responsável, como mostrou Gregori, pelo fracasso da iniciativa.

A tese de doutorado de Jullyane Brasilino, "Portas de Entrada para a Saída do Inferno" (2014), estudou recentemente a rede de serviços de atendimento à mulher em situação de violência oferecidos pelo Município de São Paulo. O trabalho mostra que os serviços da rede, a despeito de serem poucos e de funcionarem de maneira precária, de fato, parecem fugir da lógica da vitimização. É muito presente a utilização do conceito de "ciclo da violência" para caracterizar a situação da mulher, conceito que aponta para a necessidade de encontrar alternativas para que as mulheres sejam capazes de deixar a situação de violência em que se encontram de maneira autônoma (Brasilino, 2014:95).

Por exemplo, no NUDEM, mantido pela Defensoria Pública do Estado de São Paulo, a estratégia relatada pela autora inclui não pressionar as mulheres a denunciarem a violência à polícia, respeitando-se o tempo de cada uma em compreender sua situação e as diversas maneiras de lidar com ela. Na Casa Elaine de Grammont, a nomenclatura utilizada "mulher em situação de 
violência" e não "vítima de violência", já indica o tipo de ação de que pretende realizar ali (Brasilino, 2014:127).

Parece realmente haver, ao menos no Município de São Paulo, um potencial para criar serviços que superem a lógica agressor-vítima e funcionem em paralelo ao sistema penal para atuar com foco nas mulheres, tendo como alvo a superação da situação de violência e não a mera punição do agressor. Tal fato indica que uma possível mobilização política em torno da implementação efetiva da parte não penal da Lei Maria da Penha poderia, de fato, contribuir para a superação da juridificação compreendida como criminalização da violência contra a mulher.

Há práticas inovadoras inscritas na realidade que poderiam ser ampliadas e generalizadas caso o movimento feminista fosse capaz de canalizar sua força para esse alvo. Não estamos diante de possibilidades institucionais utópicas, mas de tendências de desenvolvimento institucional reais, inscritas nas práticas sociais atuais. Sonho maior, diria Amelinha, pois encarnado.

Para além dos limites deste texto, que procurou tratar dos dilemas institucionais presentes na literatura sobre a violência contra a mulher, em especial sobre a Lei Maria da Penha, há outras questões jurídico-políticas relacionadas ao tema que se insinuam nesta análise. Por exemplo, no universo dos textos examinados aqui, a discussão sobre a distinção entre violência contra a mulher e violência de gênero, da qual a violência contra a mulher seria uma das expressões (Saffioti, 2004) parece não ocupar o centro do palco.

A começar pela fala de Maria Amélia Telles, Amelinha, o debate sobre violência contra a mulher parece se limitar, de fato, ao gênero "mulher" e, dessa maneira, contribuir para reiterar a importância da esfera da família e da figura da mãe no debate sobre a violência doméstica. A ausência de uma crítica mais radical ao conceito de família no Brasil de hoje (lembremos dos textos presentes em Canevacci, 1981), um conceito que foi central 
até mesmo para o julgamento pelo STF da possibilidade de união entre pessoas do mesmo sexo, parece ser uma lacuna importante na literatura que examinamos aqui.

O problema da distinção entre violência de gênero $e$ violência contra a mulher também aparece com força nas controvérsias sobre a possibilidade de utilizar a Lei Maria da Penha para combater a violência direcionada a homens e a pessoas que expressam seu gênero de maneiras diferentes da mulher.

Trata-se de saber, nesse caso, se esse diploma legal e suas instituições devem ou não ser utilizados para proteger a violência em razão de gênero em geral, seja ela qual for. Não há espaço aqui para tratar deste tema, que ainda não foi abordado de maneira organizada em uma análise acadêmica que reunisse os casos judiciais sobre o assunto, os comentários da doutrina jurídica $e$ as diversas posições que agentes sociais variados expressam na esfera pública, em especial no interior do movimento feminista.

\section{Referências bibliográficas}

ALMEIDA, Suely Souza de. Femicídio: algemas (in)visíveis do públicoprivado. Rio de Janeiro, Revinter, 1998.

AZEVEDO, Rodrigo Ghiringhelli de. Sistema penal e violência de gênero: análise sociojurídica da Lei 11.340/06. Sociedade e Estado, vol. 23, $\mathrm{n}^{\circ}$ 1, Brasília, 2008, pp.113-135.

BANDEIRA, Lourdes. Três décadas de resistência feminista contra o sexismo e a violência feminina no Brasil: 1976 a 2006. Sociedade e Estado, vol. 24, n 1 , Brasília, 2009, pp.401-438.

BRASIL. Lei n.11.340, de 7 de agosto de 2006. Cria mecanismos para coibir a violência doméstica e familiar contra a mulher, nos termos do $\S 8^{\circ}$ do art. 226 da Constituição Federal e dá outras providências. [http://www.planalto.gov.br/CCIVIL/ Ato20042006/2006/Lei/L11340.htm - acesso em: 24 fev. 2013. 
BRASILINO, Jullyane. Portas de Entrada para a Saída do Inferno: A Rede de Serviços de Atenção para Mulheres em Situação de Violência. Tese de Doutorado, PUC São Paulo, São Paulo, 2014, mimeo.

Brown, Wendy; HalleY, Janet (Eds.). Left Legalism/Left Critique. Durham, N.C., Duke University Press, 2002.

BROWN, Wendy. Suffering the paradoxes of rights. In: BROWN, Wendy; HALLEY, Janet (Eds.). Left Legalism/Left Critique. Durham, N.C., Duke University Press, 2002, pp.420-434.

ButLER, Judith. Excitable Speech: A Politics of Performative. New York \& London, Routledge, 1997.

O parentesco é sempre tido como heterossexual? Cadernos Pagu (21), Campinas, Núcleo de Estudos de Gênero-Pagu/Unicamp, 2003, pp.219-260.

CAmPOS, Carmen Hein de Campos. Direitos humanos, violência de gênero e direito penal. 2007, mimeo [www.articulacaodemulheres.org.br/amb/adm/uploads/anexos/DH_V G_e_DP_Lei_Maria_da_Penha.pdf - acesso em: 24 fev. 2013].

CARNEVACCI, Massimo. Dialética da Família. Gênese, Estrutura e Dinâmica de uma Instituição Repressiva. São Paulo, Brasiliense, 1981.

CORTIZO, Maria del Carmen; GoYeneCHE, Priscila. Judiciarização do privado e violência contra a mulher. Revista Katálysis vol. $13, \mathrm{n}^{\circ} 1$, Florianópolis, 2010, pp.102-109.

COVER, Robert M. Narrative, Violence and the Law. Ann Arbor, University of Michigan Press, 1995.

Debert, Guita Grin; GREGORI, Maria Filomena. Violência e gênero: Novas propostas, velhos problemas. Revista Brasileira de Ciências Sociais n 66, São Paulo, 2008, pp.165-185.

Debert, Guita Grin; BerAldo de OliveirA, Marcella. Os modelos conciliatórios de solução de conflitos e a "violência doméstica". Cadernos Pagu (29), Campinas, Núcleo de Estudos de GêneroPagu/Unicamp, 2007, pp.305-377.

FouCAUlt, Michel. Microfísica do poder. São Paulo, Ed. Graal, 1979. 
FRIEDMAN, Lawrence M. Jurisdicização. In: ARNAUD, André-Jean (org.). Dicionário enciclopédico de teoria e sociologia do direito. Rio de Janeiro, Renovar, 1999, pp.437-440.

GREGori, Maria Filomena. Cenas e queixas: um estudo sobre mulheres, relações violentas e prática feminista. Rio de Janeiro, Paz e Terra, 1993.

GÜNTHER, Klaus. Responsabilização na sociedade civil. Novos Estudos CEBRAP n 63, São Paulo, CEBRAP, 2002, pp.105-118.

HABERMAS, Jürgen. Direito e Democracia: entre facticidade e validade. Rio de Janeiro, Tempo Brasileiro, 1997.

MACHADO, Marta Rodrigues de Assis. Responsabilidade Penal da Pessoa Jurídica. Brasília, Secretaria de Assuntos Legislativos, 2009. Série Pensando o Direito $\mathrm{n}^{\circ} 18$.

MACIEL, Débora Alves. Ação coletiva, mobilização do direito e instituições políticas. Revista Brasileira de Ciências Sociais $n^{\circ} 77$, São Paulo, 2011, pp.97-111.

MARX, Karl. Miséria da Filosofia. São Paulo, Expressão Popular, 2009.

NeumanN, Franz. O Império do Direito. São Paulo, Quartier Latin, 2013.

NOBRE, Marcos; RodRIGUEZ, José Rodrigo. Igualdade de Direitos entre Mulheres e Homens. Brasília, Secretaria de Assuntos Legislativos, 2009. Série Pensando o Direito, $n^{\circ} 11$.

NOBRE, Maria Teresa; Barreira, Cesar. Controle social e mediação de conflitos: as delegacias da mulher e a violência doméstica. Sociologias $n^{\circ} 20$, Porto Alegre, 2008, pp.138-163.

POUGY, Lilia Guimarães. Desafios políticos em tempos de Lei Maria da Penha. Revista Katálysis vol. 13, n 1, Florianópolis, 2010, pp.76-85.

RODRIGUEZ, José Rodrigo. Fuga do Direito: um estudo sobre o direito contemporâneo a partir de Franz Neumann, São Paulo, Saraiva, 2009.

- A desintegração do status quo: direito e lutas sociais. Novos Estudos CEBRAP no 96, São Paulo, CEBRAP, Julho de 2013, pp. 49-66. 
. Luta por Direitos, Rebeliões e Democracia no Sec. XXI: Algumas Tarefas Para a Pesquisa em Direito. Streck, Lenio Luiz; ROCHA, Leonel Severo Rocha; ENGELMANN, Wilson. (Org.), Constituição, Sistemas Sociais e Hermenêutica. Porto Alegre, Livraria do Advogado, 2014, pp.125-156.

SAFFIOTI, Heleieth. Gênero, patriarcado, violência. São Paulo, Perseu Abramo, 2004.

SARTI, Cynthia Andersen. A Família como Espelho: um estudo sobre a moral dos pobres. São Paulo, Cortez, 2012. 